\title{
PROTON MR SPECTROSCOPY OF THE FORAMEN OF MONRO REGION IN PATIENTS WITH TUBEROUS SCLEROSIS COMPLEX
}

\author{
Arnolfo de Carvalho-Neto', Isac Bruck², Sérgio A. Antoniuk², Edson Marchiori ${ }^{2}$ Emerson L. Gasparetto ${ }^{3}$
}

\begin{abstract}
Purpose: To evaluate with $1 \mathrm{H}$-magnetic resonance spectroscopy (MRS) the metabolites rations of the foramen of Monro's region in patients with tuberous sclerosis complex (TSC). Method: Twelve patients with TSC and an age and gender-matched control group underwent MR imaging at a 1.5T scanner, and 1H-MRS at the foramen of Monro level with a multivoxel acquisition. Similar volumes of interest were selected in each side of the foramen of Monro and in the basal ganglia (lentiform nuclei). The obtained $\mathrm{N}$-acetylaspartate (NAA), creatine ( $\mathrm{Cr}$ ) and choline (Cho) peak amplitude values and ratios were studied. The statistical analysis was performed and $p<0.05$ was considered statically significant. Results: There was no significant difference between the NAA/Cr and Cho/ $\mathrm{Cr}$ ratios near to the foramen of Monro and basal ganglia of the TSC patients compared with the controls ( $p>0.05$ ). Conclusion: The NAA/ $\mathrm{Cr}$ and $\mathrm{Cho} / \mathrm{Cr}$ ratios near to the foramen of Monro and basal ganglia of TSC patients are similar to the rations obtained in the control group.
\end{abstract}

KEY WORDS: tuberous sclerosis complex, magnetic resonance imaging, proton spectroscopy.

\begin{abstract}
Espectroscopia de prótons por RM da região do forame de Monro em pacientes com complexo esclerose tuberosa

Resumo - Objetivo: Avaliar através de espectroscopia de prótons as relações dos metabólitos da região do forame de Monro em pacientes com complexo esclerose tuberosa (CET). Método: Doze pacientes com CET e um grupo controle pareado por sexo e idade realizaram RM em aparelho de 1,5T, e a espectroscopia de prótons foi obtida ao nivel do forame de Monro com aquisição multi-voxel. Volumes de interesse similares foram posicionados em cada lado do forame de Monro e nos gânglios da base (núcleos lentiformes). Os valores das relações e amplitudes de pico do $\mathrm{N}$-acetilaspartato (NAA), creatina ( $\mathrm{Cr}$ ) e colina (Cho) foram estudados. A análise estatística foi realizada e valores de $p<0,05$ foram considerados estatisticamente significativos. Resultados: Não houve diferença significativa entre as relações NAA/Cr e Cho/ Cr na região do forame de Monro e nos gânglios da base dos pacientes com CET comparados com os controles $(\mathrm{p}>0,05)$. Conclusão: As relações NAA/Cr e Cho/ $\mathrm{Cr}$ na região do forame de Monro e nos gânglios da base de pacientes com CET são semelhantes àquelas obtidas no grupo controle.
\end{abstract}

PALAVRAS-CHAVE: complexo esclerose tuberosa, imagem por ressonância magnética, espectroscopia de prótons.

Tuberous sclerosis complex (TSC) is an autosomal dominant disease with incidence of 1:10000 in North America. It is characterized by hamartomatous benign tumors in multiple organs ${ }^{1-3}$. Central nervous system (CNS) involvement in TSC invariably presents with cortical tubers, subependymal glial nodules, white matter hamartomas and subependymal giant cell astrocytoma (SGCA). Neurological manifestations range from slight or even inexistent to extremely severe symptoms. The most common neu- rological finding is seizure, however other manifestations such as mental retardation in different degrees and obstructive hydrocephaly secondary to the SGCA growth are frequently seen ${ }^{1,3-5}$.

Imaging techniques, especially brain MR imaging and $\mathrm{CT}$, are well established for the diagnosis and follow up of TSC patients ${ }^{4-6}$. In addition, advanced MR imaging techniques, such as proton magnetic resonance spectroscopy (1H-MRS), which allow non-invasive biochemical evalua-

Departments of Radiology' and Neuropediatrics², University of Parana, Curitiba PR, Brazil; and Department of Radiology, University of Rio de Janeiro, Rio de Janeiro RJ, Brazil ${ }^{3}$.

Received 16 January 2008, received in final form 31 March 2008. Accepted 26 April 2008. 
tion of the brain, have been studied in TSC patients. Reduced $\mathrm{N}$-acetylaspartate/creatinine (NAA/Cr) ratio in the cortical tubers has been reported ${ }^{7-9}$, reflecting the presence of immature neurons and glia, or gliosis.

One of the most important complications in patients with TSC is the growth of SGCA near to the foramen of Monro. Several studies have proposed that these tumors could arise from subependymal nodules ${ }^{10,11}$. In a previous report, the 1H-MRS of a proven SGCA showed high choline $(\mathrm{Cho} / \mathrm{Cr})(1.60)$ and low NAA/Cr (0.93) ratios, similar to other brain neoplasms ${ }^{12}$. The authors suggested the $1 \mathrm{H}-$ MRS might be a valuable tool for early detection of neoplastic transformation in subependymal nodules arising near to the foramen of Monro in TSC patients. However, no other studies assessed the 1H-MRS features in this region, trying to define wherever the presence of non-neoplastic subependymal nodules and/or calcifications, frequently seen near to the foramen of Monro, could limit the use of the 1H-MRS for the follow up of TSC patients.

We aimed to study the foramen of Monro's region of TSC patients with 1H-MRS, trying to assess if there is any difference on the metabolites ratios comparing patients with and without non-neoplastic nodules in this area and healthy controls. We hypothesize that the metabolites ratios in patients with TSC and non-neoplastic subependymal nodules will be different from those cases without nodules, as well as from the healthy controls. As a result, we believe that these ratios seen in patients with nonneoplastic nodules could be used in the follow-up of TSC patients, aiming early diagnosis of SGCA.

\section{METHOD}

\section{Studied population}

Twelve patients with TSC ( 9 females and 3 males; mean age 11.8 years, standard deviation (SD) 2.88) were prospectively recruited. All subjects had TSC diagnosed by standard criteria ${ }^{13}$. An age and gender paired control group composed of fifteen healthy volunteers (11 females and 4 males; mean age 11.3 years, SD 2.74) was also selected. The control group was recruited after a complete clinical history and detailed physical and neurological examinations, aiming to exclude CNS diseases. The patients and their parents received information regarding the purposes of the study, answered a clinical protocol, and signed the informed consent. The study was approved by the Institutional Review Board of our hospital.

All TSC patients underwent brain CT scan with standard technique as a routine follow-up. Two independent radiologists evaluated these exams and compared with previous CT scans trying to define alterations in the size, enlargement or contrast enhancement of the lesions near to the foramen of Monro. No patients had clinical or imaging evidence of SGCA.

\section{MR imaging protocol}

All patients underwent MR imaging at a 1.5T scanner (GE Healthcare, Milwaukee, Wis, USA). Morphologic evaluation was performed and the following sequences were obtained: fluid attenuation inversion recovery (FLAIR) (repetition time (TR) $=8800$ $\mathrm{ms}$; echo time $(T E)=95 \mathrm{~ms}$; inversion time $(\mathrm{TI})=2200 \mathrm{~ms}$; section thickness $=5 \mathrm{~mm})$, spin echo $\mathrm{T} 1$ weighted $(T R=500 \mathrm{~ms}, T E=9$ ms; section thickness $=5 \mathrm{~mm}$ ) and gradient echo $\mathrm{T} 2^{*}$ weighted ( $T R=400 \mathrm{~ms}, T E=15 \mathrm{~ms}$, flip angle=20; section thickness=5 mm) in the axial plane.

\section{H-MRS acquisition}

Before the 1H-MRS image acquisition, to achieve magnetic field homogenization, the magnet was automatically shimmed on the water signal of the volume of interest (VOI) to a line width of about $8 \mathrm{~Hz}$. The proton MR spectroscopy was performed in the axial plan at the foramen of Monro level, with a multivoxel acquisition using a point-resolved spectroscopy sequence technique. The $1 \mathrm{H}-\mathrm{MRS}$ parameters were the following: section thickness $=10 \mathrm{~mm}, \mathrm{TR}=1000 \mathrm{~ms}, \mathrm{TE}=144 \mathrm{~ms}, \mathrm{FOV}=18 \mathrm{~cm}$, matrix $=18 \times 18$, NEX $=1$ and $16 \times 16$ phase encoding steps.

\section{H-MRS post-processing}

The 1H-MRS data sets were transferred to a workstation and processed with the spectroscopy analysis software Functool 2 (GE Healthcare, Milwaukee, Wis, USA). The post-processing procedure consisted of the following steps: zero filling, filtering (Hanning), 2D fast Fourier transformation, frequency shift correction, baseline correction and phase correction with constant phase angle.

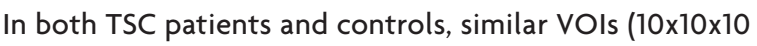
$\mathrm{mm}^{3}$ ) were selected in each side of the foramen of Monro. In addition, VOls were defined bilaterally in the basal ganglia (lentiform nuclei). As these regions were not affect by the disease and their metabolites concentration are constant with age, we used them as internal control.

To perform the metabolite quantification, the three major resonances in the spectra ( $\mathrm{N}$-acetylaspartate [NAA] at $2.02 \mathrm{ppm}$, creatine $[\mathrm{Cr}]$ at $3.03 \mathrm{ppm}$ and choline [Cho] at $3.23 \mathrm{ppm}$ ) were curve-fitted, and peak amplitude values were obtained from all voxels. The NAA, Cho and $\mathrm{Cr}$ peak amplitude values were used to calculate metabolite signal ratios of $\mathrm{NAA} / \mathrm{Cr}$ and $\mathrm{Cho} / \mathrm{Cr}$.

\section{H-MRS and MR imaging analysis}

Based on the CT scans and conventional MR images, the following morphologic abnormalities were assessed: calcification and/or subependymal nodules near to the foramen of Monro, cortical tubers and subependymal nodules in other locations. In addition, the quality of the spectra was evaluated, considering the base line and the peak width patterns. 
Table. Comparison of the NAA/Cr and Cho/Cr ratios in TSC patients $(n=12)$ and control group $(n=15)$.

\begin{tabular}{|c|c|c|c|}
\hline 1H-MRS ratio & $\begin{array}{c}\text { TSC patients } \\
\text { (Mean } \pm S D)\end{array}$ & $\begin{array}{l}\text { Control group } \\
\text { (Mean } \pm \text { SD) }\end{array}$ & $p$ value \\
\hline \multicolumn{4}{|c|}{ Right foramen of Monro } \\
\hline $\mathrm{NAA} / \mathrm{Cr}$ & $1.29 \pm 0.54$ & $1.60 \pm 0.59$ & 0.1877 \\
\hline $\mathrm{Cho} / \mathrm{Cr}$ & $1.26 \pm 0.39$ & $1.67 \pm 0.69$ & 0.2416 \\
\hline \multicolumn{4}{|c|}{ Left foramen of Monro } \\
\hline $\mathrm{NAA} / \mathrm{Cr}$ & $1.35 \pm 0.61$ & $1.59 \pm 0.38$ & 0.4945 \\
\hline $\mathrm{Cho} / \mathrm{Cr}$ & $1.34 \pm 0.50$ & $1.61 \pm 0.48$ & 0.4350 \\
\hline \multicolumn{4}{|c|}{ Right basal ganglia } \\
\hline $\mathrm{NAA} / \mathrm{Cr}$ & $1.79 \pm 0.48$ & $1.96 \pm 0.45$ & 0.6256 \\
\hline Cho/Cr & $1.16 \pm 0.28$ & $1.23 \pm 029$ & 0.9611 \\
\hline \multicolumn{4}{|c|}{ Left basal ganglia } \\
\hline $\mathrm{NAA} / \mathrm{Cr}$ & $1.60 \pm 0.54$ & $1.95 \pm 0.35$ & 0.3798 \\
\hline Cho/Cr & $1.16 \pm 0.33$ & $1.26 \pm 0.29$ & 0.8836 \\
\hline
\end{tabular}

\section{Statistical analysis}

The statistical analysis was performed using the software STATA, version 8 (Stata corporation, Texas, USA). The NAA/Cr and $\mathrm{Cho} / \mathrm{Cr}$ rations were analyzed through a non-parametric Mann-Whitney test. In addition, a chi-squared test was used for categorical variables. Values of $\mathrm{p}<0.05$ were considered statically significant.

\section{RESULTS}

Regarding the conventional MR imaging findings, seven TSC patients (58.3\%) had areas of low signal intensity on T2*-weighted images near to the foramen of Monro ( 4 unilateral and 3 bilateral), suggesting the presence of calcifications. In four patients, six subependymal nodules (ranging from 8 to $12 \mathrm{~mm}$ ) were seen in this region. All TSC patients had cortical tubers (ranging from 20 to 39) and subependymal nodules other than near to the foramen of Monro (ranging from 3 to 12).
The 1H-MRS spectra were considered of low quality near to the foramen of Monro in five TSC patients. There was a positive relation between the presence of calcification near to the foramen of Monro and low quality spectra $(p=0.0214)$.

There was no significant difference between the NAA/ $\mathrm{Cr}$ and $\mathrm{Cho} / \mathrm{Cr}$ ratios near to the foramen of Monro and basal ganglia of the TSC patients $(n=12)$ compared with the controls ( $n=15)$ (Table). Even when excluded the spectra considered as low quality $(n=5)$, comparing the remaining 7 cases with the controls, no significant differences were seen for both ratios ( $p>0.05$ ).

In addition, we evaluated the NAA/Cr and Cho/Cr ratios obtained near of the foramen of Monro only in TSC patients $(n=12)$, comparing the ratios in areas with $(n=18)$ or without subependymal nodules $(n=6)$, and no significant difference ( $p>0.05$ ) was demonstrated in both ratios (Figure).
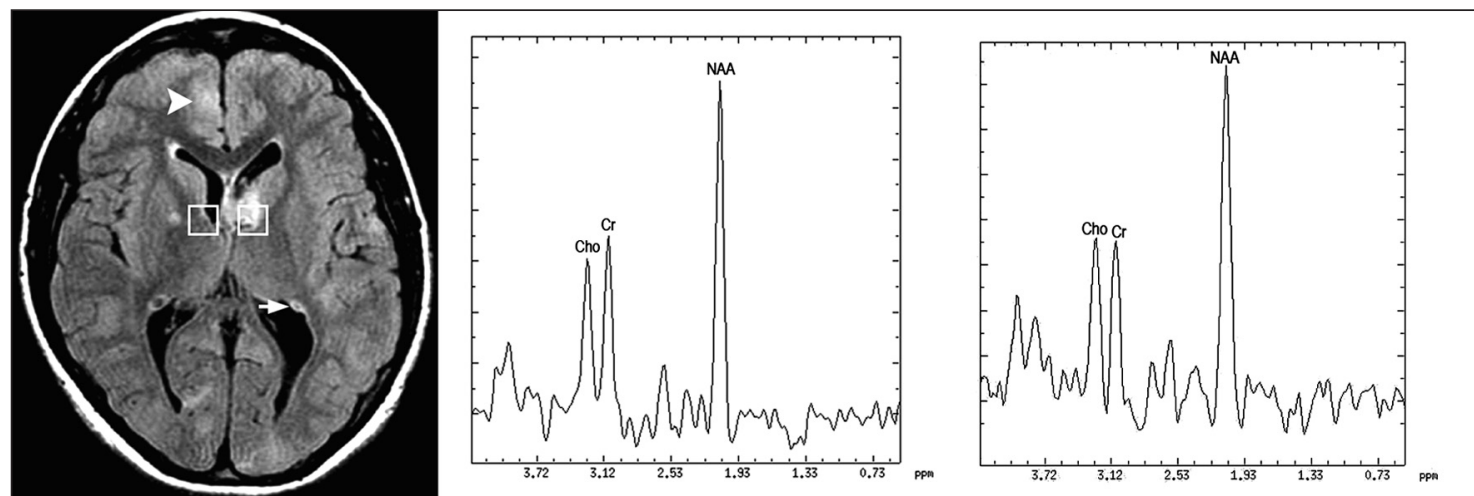

Figure. (A) FLAIR sequence at the level of the foramen of Monro shows cortical tubers (arrowhead) and subependymal nodules (arrow) in the temporal horns of the lateral ventricles and at the left foramen of Monro region. The selected volumes of interest are shown at the right and left foramen of Monro region. $1 \mathrm{H}-\mathrm{MRS}$ obtained at the right (B) and left (C) foramen of Monro region. 


\section{DISCUSSION}

In this study, we have demonstrated that the NAA/Cr and $\mathrm{Cho} / \mathrm{Cr}$ ratios near to the foramen of Monro of TSC patients are similar to the healthy controls. Even when excluding spectra with low quality, probably related to calcifications in this region, no significant difference was demonstrated. In addition, we found similar NAA/Cr and Cho/Cr ratios near to the foramen of Monro of TSC patients when comparing cases with or without subependymal nodules in this region. The NAA/Cr and $\mathrm{Cho} / \mathrm{Cr}$ ratios demonstrated in this series can be used as reference values for the follow up of TSC patients, aiming early diagnosis of SGCA, which could present with high $\mathrm{Cho} / \mathrm{Cr}$ and low NAA/Cr ratios on the $1 \mathrm{H}-\mathrm{MRS}^{12}$.

The neoplastic degeneration of subependymal nodules in patients with TSC is a well-known complication. The diagnostic definition of SGCA is not based only on histological findings because they are similar to the other subependymal nodules and cortical tubers ${ }^{14,15}$. As a result, previous studies have investigated the MR imaging findings that could be associated with neoplastic degeneration of the subependymal nodules. Significant changes in the size or the pattern of contrast enhancement of the lesions were suggested as determinant imaging factors ${ }^{14,15}$. In addition, the association of conventional and advanced MR imaging techniques, such as $1 \mathrm{H}-\mathrm{MRS}$, could allow even earlier diagnosis of SGCA.

$1 \mathrm{H}-\mathrm{MRS}$ of brain enables noninvasive quantification of metabolites in vivo ${ }^{16}$. The most intense signal in the proton MR spectrum of brain originates from the $\mathrm{N}$-acetyl groups, mainly $\mathrm{N}$-acetylaspartate. Less intense signals arise from creatine plus phosphocreatine and cholinecontaining compounds. NAA is identified exclusively in neurons and neuronal processes in the mature brain and can be used as a neuronal marker. Decreased NAA is observed in areas of neuronal loss or dysfunction. $\mathrm{Cr}$, which is more concentrated in glia than neurons, is relatively homogeneously distributed in normal brain and can be used as an internal standard in this circumstance. Cho is a component of phosphoglyceride and is therefore a major constituent of cell membranes. The Cho can increase in conditions associated with increased cell membrane turnover, such as neoplasms $\mathrm{s}^{7,8,16,17}$.

Several authors have studied the 1H-MRS features of cortical tubers in patients with TSC. In most of the cases they have found reduced NAA/Cr ratio, reflecting the presence of immature neurons and glia, or gliosis ${ }^{7-9,18}$. Mukonoweshuro et al. ${ }^{8}$ studied 26 TSC patients with $1 \mathrm{H}-\mathrm{MRS}$ and demonstrated low NAA/Cr and NAA/Cho ratios in the cortical tubers compared with normal-appearing brain areas. Mizuno et al. ${ }^{9}$ evaluated the $1 \mathrm{H}-\mathrm{MRS}$ features in four patients with TSC and observed decreased $\mathrm{NAA} / \mathrm{Cr}$ and increased myoinositol/Cr ratios. Sener ${ }^{18} \mathrm{re-}$ ported reduced NAA/Cr ratio and increased Cho/Cr ratio in a cortical tuber. A control study performed seven months later, however, showed reduced NAA/Cr ratio and a slightly increased $\mathrm{Cho} / \mathrm{Cr}$ ratio. None of these studies investigated the metabolites ratios in the subependymal nodules near to the foramen of Monro.

As far as we know, only two studies assessed the $1 \mathrm{H}$ MRS findings of subependymal nodules in TSC patients. Tarasów et al. ${ }^{19}$ found reduced NAA/Cr and slight increased $\mathrm{Cho} / \mathrm{Cr}$ ratios, but the exact location of the nodule was not mentioned. A recent study reported a case of TSC presenting with a $15 \mathrm{~mm}$ nodule at the left foramen of Monro $^{12}$. The lesion had heterogeneous signal on $\mathrm{T} 1$ and T2weighted images, and strong enhancement after contrast administration. The 1H-MRS (multi-voxel PRESS, TE=144ms) showed high $\mathrm{Cho} / \mathrm{Cr}$ and low NAA/Cr ratios in the lesion, compared with the contralateral foramen of Monro region ( $\mathrm{Cho} / \mathrm{Cr}=1.6$ vs. 1.29 and $\mathrm{NAA} / \mathrm{Cr}=0.93$ vs. 1.56 ). The diagnosis of SGCA was defined through histological examination, and the authors suggested that $1 \mathrm{H}-\mathrm{MRS}$ could be a valuable tool for the early detection of neoplastic transformation of subependymal nodules in TSC patients.

However, no previous studies investigated if the nonneoplastic subependymal nodules and calcifications, frequently seen in the region near to the foramen of Monro of TSC patients, could limit the use of the $1 \mathrm{H}-\mathrm{MRS}$ as a follow up technique. In this series, the NAA/Cr and Cho/ $\mathrm{Cr}$ ratios near to the foramen of Monro of TSC patients were similar to the controls. Even when excluding spectra with low quality, related to presence of calcifications, or when comparing cases with or without non-neoplastic subependymal nodules in this region, no significant difference was demonstrated.

Limitations of this study were related to the small number of patients investigated, as the TSC is a quite common syndrome. However, we only included patients able to undergo the MRI without sedation, excluding cases younger than six years old or with severe mental retardation. In addition, we had no histological diagnosis in the patients with non-neoplastic subependymal nodules, although those nodules did not fill the literature diagnostic criteria for SGCA. Moreover, we had several technical limitations, as the applications for acquisition and post-processing of 1-H-MRS have improved significantly during the progress of the study. However, aiming a methodological standardization of our data, we decided to study all the patients in the same MR scanner. Also, we have studied long echo time (144 ms) 1H-MRS, and myinositol peak, which was not evaluated because it is better 
demonstrated with short echo $1 \mathrm{H}-\mathrm{MRS}$, could be helpful in predicting malignant transformation to SCGA. Finally, because the size of the analyzed 1H-MRS VOI $110 \times 10 \times 10$ $\mathrm{mm}^{3}$ ), one can argue that small lesions can be missed, what could explain the absence of difference of the ratios between foramina with or without nodules. In addition, we did not account for the effect of volume averaging with CSF and normal brain in subcentimiter nodules. However, the non-homogeneity of this region related to the bone and air of the skull base and sphenoid sinus not allowed smaller voxels, as we tried to use a technique compatible with daily practice without sedation.

In conclusion, the NAA/Cr and $\mathrm{Cho} / \mathrm{Cr}$ ratios near to the foramen of Monro and basal ganglia of TSC patients are similar to the rations obtained in the same regions of the control group. Even when excluded the spectra of low quality, mainly related to calcifications in this area, or when comparing foramina with and without non-neoplastic subependymal nodules, no significant differences were seen for both rations. The NAA/Cr and $\mathrm{Cho} / \mathrm{Cr}$ ratios obtained with $1 \mathrm{H}-\mathrm{MRS}$ are reproducible and robust. Therefore this imaging technique can potentially be used for screening and follow-up of TSC patients, and the ratios demonstrated in this series can be used as reference values, aiming early diagnosis of neoplastic degeneration of subependymal nodules. Further 1H-MRS studies must be conduced with long term follow-up of non-neoplastic lesions near to the foramen of Monro, in order to define the real potential of this technique for early diagnosis of SGCA in patients with TSC.

\section{REFERENCES}

1. Caldemeyer KS, Mirowski GW. Tuberous sclerosis: Part I. Clinical and central nervous system findings. J Am Acad Dermatol 2001;45:448-449.
2. O'Callaghan FJ, Osborne JP. Advances in the understanding of tuberous sclerosis. Arch Dis Child 2000;83:140-142.

3. Sparagana SP, Roach ES. Tuberous sclerosis complex. Curr Opin Neurol 2000;13:115-119.

4. Takata K, Gasparetto EL, Costa Leite C, et al. Subependymal giant cell astrocytoma in patients with tuberous sclerosis: magnetic resonance imaging findings in ten cases. Arq Neuropsiquiatr 2007;65:313-316.

5. Ridler K, Bullmore ET, De Vries PJ, et al. Widespread anatomical abnormalities of grey and white matter structure in tuberous sclerosis. Psychol Med 2001;31:1437-1446.

6. Christophe C, Sekhara T, Rypens F, Ziereisen F, Christiaens F, Dan B MRI spectrum of cortical malformations in tuberous sclerosis complex. Brain Dev 2000;22:487-493.

7. Li LM, Cendes F, Bastos AC, Andermann F, Dubeau F, Arnold DL. Neuronal metabolic dysfunction in patients with cortical developmental malformations: a proton magnetic resonance spectroscopic imaging study. Neurology 1998;50:755-759.

8. Mukonoweshuro W, Wilkinson ID, Griffiths PD. Proton MR spectroscopy of cortical tubers in adults with tuberous sclerosis complex. AJNR Am J Neuroradiol 2001;22:1920-1925.

9. Mizuno S, Takahashi Y, Kato Z, Goto H, Kondo N, Hoshi H. Magnetic resonance spectroscopy of tubers in patients with tuberous sclerosis. Acta Neurol Scand 2000;102:175-178.

10. Beems T, Grotenhuis JA. Subependymal giant-cell astrocytoma in tuberous sclerosis: endoscopic images and the implications for therapy. Minim Invasive Neurosurg 2001;44:58-60.

11. Nishio S, Morioka T, Suzuki S, Kira R, Mihara F, Fukui M. Subependymal giant cell astrocytoma: clinical and neuroimaging features of four cases. J Clin Neurosci 2001:8:31-34.

12. Carvalho-Neto A, Gasparetto EL, Bruck I. Subependymal giant cell astrocytoma with high choline/creatine ratio on proton MR spectroscopy. Arq Neuropsiquiatr 2006;64:877-880.

13. Jozwiak S, Schwartz RA, Janniger CK, Bielicka-Cymerman J. Usefulness of diagnostic criteria of tuberous sclerosis complex in pediatric patients. J Child Neurol 2000;15:652-659.

14. Curatolo P, Verdecchia M, Bombardieri R. Tuberous sclerosis complex: a review of neurological aspects. Eur J Paediatr Neurol 2002;6:15-23.

15. Nabboutt R, Santos M, Roland Y, et al. Early diagnosis of subependimal giant cell astrocytoma in children with tuberous sclerosis. J Neurol Neurosurg Psychiatry 1999;66:370-375.

16. Aasly J, Silfvenius H, Aas TC, et al. Proton magnetic resonance spectroscopy of brain biopsies from patients with intractable epilepsy. Epilepsy Res 1999;35:211-217.

17. Barkovich AJ. An approach to MRI of metabolic disorders in children. J Neuroradiol 2007;34:75-88

18. Sener RN. Infantile tuberous sclerosis changes in the brain: proton MR spectroscopy findings. Comput Med Imag Graph 2000;24:19-24.

19. Tarasów E, Kubas B, Walecki J. MR proton spectroscopy in patients with CNS involvement in Bourneville's disease. Med Sci Monit 2001;7:762-765. 